Original Article

\title{
Water-in-Oil-in Water (W/O/W) Double Emulsion Formulations using Variation Concentration of Carboxymethyl Cellulose Sodium
}

\section{Formulasi Emulsi Ganda Air dalam Minyak dalam Air (A/M/A) dengan Variasi Konsentrasi Carboxymethyl Cellulose Sodium}

\author{
Devi Tania, Marchaban, dan Rina Kuswahyuning* \\ Faculty of Pharmacy, Universitas Gadjah Mada, Yogyakarta, Indonesia \\ *Corresponding author: Rina Kuswahyuning | Email: rinakus@ugm.ac.id
}

Received: 25 September 2020; Revised: 23 October 2020; Accepted: 26 October 2020; Published: 26 October 2020

\begin{abstract}
Hydrocolloid macromolecules are considered capable of stabilizing water-in-oil-in-water (W/O/W) double emulsion. This study aimed to formulate and evaluate W/O/W double emulsions using variation concentration of sodium carboxymethyl cellulose (CMC Na). Water-in-oil (W/O) primary emulsion was prepared with liquid paraffin as the oil phase and span 80 as the emulgator at varying concentration i.e. 5, 10, 15 , and $20 \%$. The W/O primary emulsions were characterized for their microscopy, viscosity, and emulsion stability after heating-cooling cycle test. Span 80 with a concentration of $15 \%$ produced the best W/O primary emulsion characteristic. Emulsification of the W/O primary emulsion into an aqueous phase containing CMC Na produced a W/O/W double emulsion. Increasing the CMC Na concentration from 1, 2, and 3\% resulted in a significant increase in the viscosity of the multiple emulsion. Oil droplet visual microscopy showed a relatively large variation of oil droplet sizes in all W/O/W double emulsions. The release of water-soluble dyes model (Ponceau 4R) from all W/O/W double emulsion showed a low percentage release (i.e. 0.06-0.09\%) after 6 hours observation indicating suitablity of this double emulsion system for a sustained release system. The W/O/W double emulsion at all concentrations of CMC Na did not separate after the stability test using the heatingcooling cycle method.
\end{abstract}

Keywords : double emulsion; stability; carboxymethyl cellulose; span 80

\begin{abstract}
Abstrak: Makromolekul hidrokoloid dinilai mampu menstabilkan emulsi ganda air-dalam minyak-dalam air (A/M/A). Penelitian ini bertujuan untuk membuat formulasi dan mengevaluasi emulsi ganda A/M/A dengan menggunakan variasi konsentrasi natrium karboksimetil selulosa (CMC Na). Emulsi primer air dalam minyak $(\mathrm{A} / \mathrm{M})$ dibuat dengan parafin cair sebagai fase minyak dan emulgator span 80 pade berbagai konsentrasi yaitu 5, 10, 15, dan 20\%. Emulsi primer A/M dievaluasi mikroskopi ukuran droplet, viskositas, dan stabilitas emulsi A/M setelah uji heating-cooling cycle. Span 80 dengan konsentrasi 15\% menghasilkan karakteristik emulsi primer $\mathrm{A} / \mathrm{M}$ yang paling baik. Emulsifikasi emulsi primer A/M ke dalam fase air yang mengandung CMC Na menghasilkan emulsi ganda A/M/A. Peningkatan konsentrasi CMC Na dari 1, 2, dan 3\% menghasilkan peningkatan viskositas emulsi ganda secara signifikan. Mikroskopi visual droplet minyak menunjukkan ukuran droplet minyak yang bervariasi pada semua emulsi ganda A/M/A. Pelepasan model zat warna larut air (Ponceau $4 \mathrm{R})$ dari semua emulsi ganda $\mathrm{A} / \mathrm{M} / \mathrm{A}$ sangat kecil (0,06-0,09\%) setelah 6 jam pengujian yang mengindikasikan
\end{abstract}


potensi penggunaan emulsi ganda ini sebagai sistem penghantaran lepas lambat. Emulsi ganda A/M/A pada semua konsentrasi CMC Na tidak memisah setelah uji stabilitas dengan metode heating-cooling cycle.

Kata kunci: emulsi ganda; stabilitas; karboksimetil selulosa; span 80

\section{PENDAHULUAN}

Emulsi ganda merupakan salah satu bentuk sistem penghantaran yang menarik untuk diaplikasikan pada obat, makanan, ataupun kosmetika [1,2]. Salah satu bentuk emulsi ganda adalah emulsi air dalam minyak dalam air (A/M/A). Pada sistem ini, droplet air internal berada dalam droplet minyak berukuran lebih besar yang terdispersikan dalam fase air fase eksternal. Tantangan utama dalam formulasi emulsi ganda terutama terkait dengan stabilitas emulsi [3].

Emulgator berperan penting dalam menentukan stabilitas emulsi ganda. Emulsi ganda A/M/A dapat dibuat menggunakan dua jenis emulgator rantai pendek lipofilik dan hidrofilik [4]. Formulasi emulsi ganda dengan pendekatan ini terkadang dihasilkan emulsi ganda yang kurang stabil yang disebabkan oleh beberapa faktor termasuk potensi adanya interaksi ataupun kompetisi emulgator yang teradsorpsi pada antar muka droplet air internal ataupun droplet minyak pada emulsi ganda. Emulgator makromolekul hidrokoloid dinilai mampu menstabilkan emulsi ganda A/M/A. Karboksimetil selulosa (CMC Na) telah diteliti penggunaannya sebagai peningkat stabilitas emulsi ganda A/M/A. Pencapaian stabilitas optimum emulsi ganda memerlukan kesesuaian antara karakter zat aktif, fase minyak, fase air, dan emulgator [2, 4-8].

CMC Na sebagai stabilisator emulsi ganda A/M/A telah dilaporkan pada emulsi ganda dengan canola oil sebagai fase minyak dan polyglyerol polyricinoleat sebagai emulgator lipofilik. Hal ini terkait dengan struktur molekul dan aktivitas tegangan antar muka CMC Na pada sistem emulsi tersebut [5]. Kemampuan stabilisasi emulsi ganda A/M/A oleh CMC Na pada jenis minyak yang lain seperti parafin cair dan kombinasinya dengan emulgator span 80 belum diketahui. Oleh karenanya, penelitian ini bertujuan untuk memformulasi dan mengevaluasi emulsi ganda A/M/A dengan parafin cair sebagai fase minyak, span 80 sebagai emulgator emulsi primer dan CMC Na sebagai emulgator/stabilisator dengan konsentrasi 1, 2, dan 3\%. Emulsi ganda A/M/A dibuat dengan cara dua tahap emulsifikasi. Emulsi primer A/M disiapkan dengan membandingkan karakteristik dan stabilitas emulsi primer A/M dengan variasi konsentrasi span 80 5-20\%. Emulsi primer A/M yang terpilih kemudian diemulsifikasikan menjadi emulsi ganda A/M/A dengan CMC Na yang divariasikan konsentrasinya (1, 2, dan 3\%). Emulsi primer dan emulsi ganda dievaluasi karakteristiknya meliputi viskositas dan mikroskopi ukuran droplet. Pengaruh tipe emulsi A/M dan A/M/A pada pelepasan zat warna model larut air (Ponceau 4R) akan diteliti. Stabilitas emulsi ganda A/M/A setelah uji heating-cooling cycle juga akan dievaluasi.

\section{BAHAN DAN METODE}

\subsection{Bahan}

Bahan-bahan yang digunakan adalah parafin cair, span 80, dan karboksimetil selulosa natrium (CMC Na) berderajad farmasetis. Zat warna yang digunakan adalah Ponceau 4R (C.I. 16255/Brilliant Scarlet 4R). 


\subsection{Pembuatan emulsi tipe air dalam minyak $(A / M)$}

Emulsi tipe A/M disiapkan dengan komposisi seperti pada Tabel 1. Parafin cair dan span 80 dicampur lalu dipanaskan hingga $70^{\circ} \mathrm{C}$ sambil diaduk sampai homogen. Fase air dibuat dengan melarutkan Ponceau 4R ke dalam air dan disonikasi 3 menit. Campuran parafin cair dan span 80 dimasukkan ke dalam larutan fase air sedikit demi sedikit sambil dilakukan pengadukan (1500 rpm selama 20 menit).

Tabel 1. Komposisi formula emulsi air dalam minyak (A/M)

\begin{tabular}{c|ccccc}
\hline \multicolumn{2}{c}{} & Bahan & \multicolumn{4}{c}{ Formula (\%)/b) } \\
\hline \multirow{2}{*}{ Fase air } & Air & 40 & 40 & 40 & 40 \\
& Ponceau 4R & 1 & 1 & 1 & 1 \\
\hline \multirow{2}{*}{ Fase } & Span 80 & 5 & 10 & 15 & 20 \\
minyak & Parafin cair & 54 & 49 & 44 & 39 \\
\hline
\end{tabular}

\subsection{Pembuatan emulsi tipe air-dalam minyak-dalam air $(A / M / A)$}

Emulsi tipe A/M/A dibuat dengan komposisi sesuai pada Tabel 2. Perbandingan emulsi primer dan fase air eksternal adalah 40:60. Fase air eksternal dibuat dengan mencampur CMC Na dengan air kemudian diaduk dan didiamkan selama 24 jam. CMC Na yang telah mengembang diaduk (250 rpm) selama 2 menit. Emulsi primer A/M yang terpilih didispersikan sedikit demi sedikit ke dalam fase eksternal sambil dilakukan pengadukan (500 rpm selama 15 menit).

Tabel 2. Komposisi formula emulsi ganda air-dalam minyak-dalam air (A/M/A)

\begin{tabular}{|c|c|c|c|c|}
\hline & \multirow{2}{*}{ Bahan } & \multicolumn{3}{|c|}{ Formula $(\% b / b)$} \\
\hline & & I & II & III \\
\hline \multirow{4}{*}{ Emulsi primer $\mathrm{A} / \mathrm{M}$} & Air & 16 & 16 & 16 \\
\hline & Ponceau 4R & 0,4 & 0,4 & 0,4 \\
\hline & Span 80 & 6 & 6 & 6 \\
\hline & Parafin cair & 17,6 & 17,6 & 17,6 \\
\hline \multirow{2}{*}{ Fase eksternal } & $\mathrm{CMC} \mathrm{Na}$ & 1 & 2 & 3 \\
\hline & Air & 59 & 58 & 57 \\
\hline
\end{tabular}

\subsection{Determinasi tipe emulsi}

Determinasi tipe emulsi dilakukan dengan uji konduktivitas. Alat uji dihubungkan ke sumber listrik kemudian elektroda dicelupkan pada emulsi yang telah dibuat. Emulsi dengan medium pendispersi air akan memiliki sifat konduktif [9]

\subsection{Evaluasi viskositas emulsi}

Sampel dimasukkan ke dalam wadah dan spindle dipastikan tercelup ke dalam wadah (menggunakan viskosimeter Brookfield). Waktu dan kecepatan putar spindle (spindle nomor 4 untuk emulsi A/M dan spindle nomor 5 untuk emulsi A/M/A) diatur sebesar 10 detik dan $100 \mathrm{rpm}$. 
2.6. Evaluasi stabilitas emulsi dengan uji heating-cooling cycle

Emulsi ganda $\mathrm{A} / \mathrm{M} / \mathrm{A}$ disimpan dalam suhu $4 \pm 0,5^{\circ} \mathrm{C}$ selama 24 jam kemudian dipindahkan ke dalam oven (suhu $40 \pm 0,5^{\circ} \mathrm{C}$ ) selama 24 jam [10]. Siklus diulangi sampai mencapai tiga siklus. Untuk emulsi A/M juga diamati pemisahan fasenya pada suhu ruang $\left(28 \pm 0,5^{\circ} \mathrm{C}\right)$ selama 30 hari. Pemisahan diamati pada masing-masing emulsi [11]. Pemisahan fase (F) dihitung dengan membandingkan tinggi akhir emulsi setelah pengamatan dibagi dengan tinggi awal emulsi.

\subsection{Evaluasi ukuran droplet}

Emulsi A/M diencerkan dengan fase eksternalnya (minyak) sebanyak 20 kali, sedangkan emulsi ganda A/M/A diencerkan dengan air sebanyak 7 kali. Emulsi diletakkan di atas object glass dan ditutup dengan gelas penutup. Droplet diamati menggunakan mikroskop cahaya dengan perbesaran 150 kali.

\subsection{Pelepasan zat warna}

Membran selofan direndam dengan air selama 2 jam. Membran selofan (Spectrapor, molecular weight cut off 6000-8000) ditempatkan di antara kompartemen donor dan aseptor. Sebanyak 3 gram emulsi ditempatkan pada kompartemen donor dan $25 \mathrm{ml}$ air di kompartemen aseptor kemudian pengaduk magnetik dijalankan pada kecepatan $120 \mathrm{rpm}$ [12]. Pengambilan sampel dilakukan pada suhu ruang $\left(28 \pm 0,5^{\circ} \mathrm{C}\right)$ sebanyak 2,0 ml pada menit ke-30, 60, 90, 120, 180, 240, dan 300 disertai pengembalian 2,0 $\mathrm{ml}$ air ke kompartemen aseptor setiap kali sampling. Serapan diukur pada panjang gelombang maksimum (508 nm) dengan spektrofotometer UV/Vis. Dihitung kumulatif bobot zat terdifusi dan persen bobot terdifusi dengan memperhitungkan faktor koreksi akibat adanya pengenceran.

\subsection{Analisis statistik}

Hasil determinasi tipe emulsi dan ukuran droplet emulsi dianalisis secara deskriptif. Data pemisahan fase dan viskositas antar konsentrasi emulgator dianalisis dengan ANOVA satu jalan, sedangkan pemisahan fase, viskositas, dan pelepasan zat warna antar tipe emulsi dianalisis dengan Independent-Samples T Test (analisis statistik dilakukakan dengan software SPSS).

\section{HASIL DAN DISKUSI}

\subsection{Emulsi air dalam minyak $(A / M)$}

Ukuran droplet merupakan salah satu faktor yang dapat menentukan stabilitas emulsi. Hasil pengamatan droplet emulsi A/M ditampilkan pada Gambar 1. Pada emulsi A/M, dengan meningkatnya konsentrasi span 80 menghasilkan ukuran droplet yang nampak semakin kecil terutama pada span 80 dengan rentang konsentrasi 5-15\%. Droplet terlihat tersebar labih merata dengan agregat droplet yang lebih sedikit pada emulsi A/M dengan span 80 konsentrasi $15 \%$. Semakin tinggi konsentrasi emulgator maka permukaan droplet akan semakin banyak tertutupi oleh emulgator sehingga mengurangi energi bebas permukaan dan ukuran droplet juga semakin kecil [13, 14]. Peningkatan konsentrasi emulgator diatas konsenstrasi kritis nya (critical micelle concentration/CMC) dapat menghasilkan ukuran droplet yang tidak lagi berubah secara signifikan. Secara mikroskopik peningkatan span 80 dari konsentrasi 15\% menjadi 20\% nampak tidak mempengaruhi ukuran droplet emulsi A/M. Ukuran droplet emulsi A/M dengan span 80 konsentrasi 20\% nampak secara visual mikroskopi tidak berbeda dengan ukuran droplet emulsi dengan span 80 
konsentrasi $15 \%$. Selain itu, emulsi primer dengan span 80 konsentrasi $20 \%$ menunjukkan adanya agregat droplet emulsi $\mathrm{A} / \mathrm{M}$ yang lebih banyak daripada emulsi dengan span 80 konsentrasi $15 \%$.

Hasil uji determinasi tipe emulsi primer menunjukkan bahwa emulsi dengan konsentrasi Span 80 sebesar 5\%, 10\%, 15\%, dan 20\% tidak menghasilkan konduktivitas pada alat uji. Emulsi A/M memiliki fase kontinyu berupa minyak sehingga tidak dapat menghantarkan arus listrik.

Viskositas merupakan salah satu faktor yang mempengaruhi pemisahan emulsi. Viskositas berbanding terbalik dengan laju pemisahan emulsi. Semakin tinggi viskositas maka laju pemisahannya akan semakin kecil. Hal ini disebabkan karena kekentalan pada fase kontinyu akan menghalangi flokulasi dan atau koalesensi fase dispers sehingga kecepatan pemisahan emulsi berkurang. Hasil pengukuran viskositas emulsi A/M ditampilkan oleh Gambar 2A. Emulsi A/M dengan konsentrasi span 80 sebesar 5, 10, 15, dan 20\% berturut-turut menunjukkan viskositas sebesar 260,0 \pm 68,6; 336,0 \pm 19,6; 494,0 \pm 39,0; dan 388,0 \pm 46,2 mPas. Kenaikan viskositas emulsi A/M sejalan dengan kenaikan konsentrasi span 80 sampai pada konsentrasi 15\%. Viskositas mengalami penuruan pada konsentrasi span 80 konsentrasi 20\%. Hasil analisis statistik menunjukkan konsentrasi span 80 $15 \%$ memiliki perbedaan viskositas yang signifikan dengan konsentrasi lainnya $(p<0,05)$. Hasil ini sesuai dengan hasil pengamatan ukuran droplet pada emulsi A/M dengan span 80 15\% yang menunjukkan ukuran droplet yang lebih kecil. Meningkatnya viskositas emulsi yang terkait dengan ukuran droplet yang kecil juga telah dilaporkan [14].
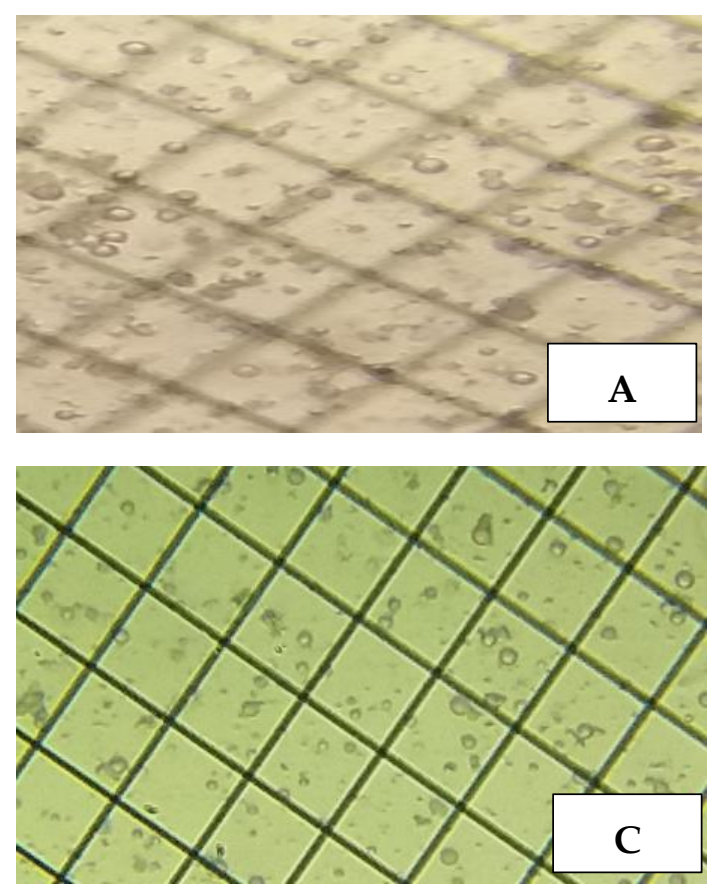
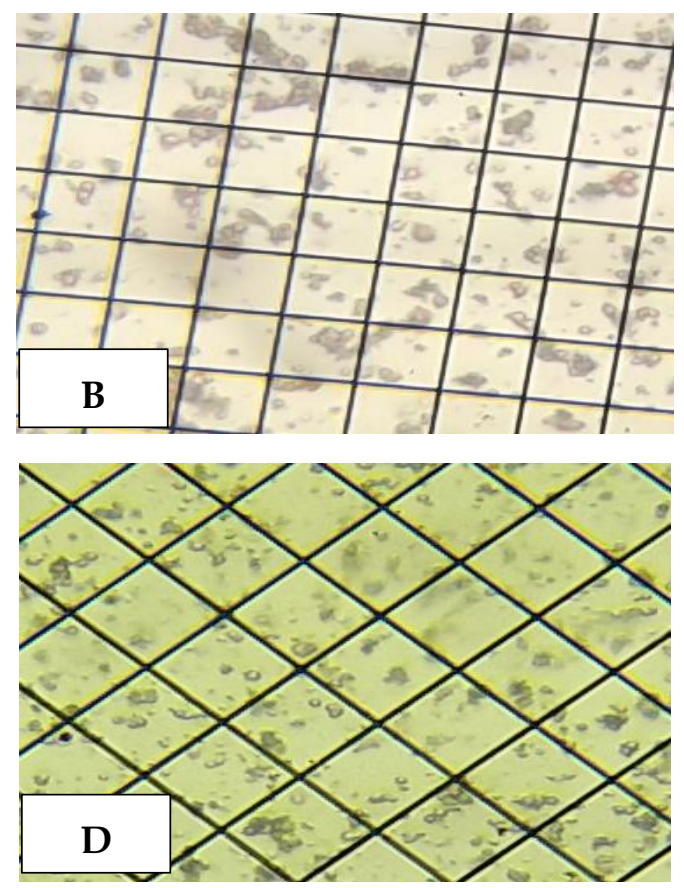

Gambar 1. Mikroskopi emulsi air dalam minyak (A/M) dengan emulgator span 80 konsentrasi 5 (A), 10 (B), 15 (C), dan 20\% (D) (dengan perbesaran mikroskop 150x)

Untuk dapat mengamati stabilitas emulsi dalam waktu singkat dapat dilakukan uji stabilitas dipercepat, yaitu dengan menempatkan emulsi pada stress conditions seperti suhu, kelembaban, cahaya, pengadukan, $\mathrm{pH}$, atau gravitasi [15]. Hasil uji pemisahan fase emulsi A/M dapat diamati pada Gambar 2B. Setelah siklus uji heating cooling cycling, emulsi primer A/M dengan span 80 konsentrasi 15\% menunjukkan emulsi yang paling stabil (nilai F paling tinggi) dibandingkan emulsi 
primer dengan span 80 konsentrasi 10\% dan 5\%. Span 80 konsentrasi 15\% menghasilkan pemisahan fase emulsi primer A/M yang tidak berbeda bermakna dengan span $8020 \%$ (p>0,05). Hasil ini sesuai dengan hasil pengamatan mikroskopi ukuran droplet emulsi A/M. Span 80 15\% menghasilkan droplet emulsi A/M yang nampak kecil. Tingginya viskositas emulsi ini juga menghambat timbulnya koelesensi dan pemisahan fase saat uji stabilitas [16]. Rasio pemisahan dengan nilai mendekati 1 yang diuji pada suhu ruang juga dihasilkan oleh emulsi A/M dengan konsentrasi span 80 15\% diikuti konsentrasi span 80 konsentrasi 20\%, 10\%, dan 5\%. Konsentrasi optimum span 80 dalam penelitian ini adalah $15 \%$. Pada konsentrasi dibawah konsentrasi optimum, kemampuan emulgator dalam menurunkan tegangan antarmuka dan membentuk lapisan film akan berkurang sehingga koalesensi berlangsung lebih besar. Pada konsentrasi span 80 di atas konsentrasi optimum, emulsi akan mengalami ketidakstabilan yang disebabkan karena koalesensi yang cepat [17].
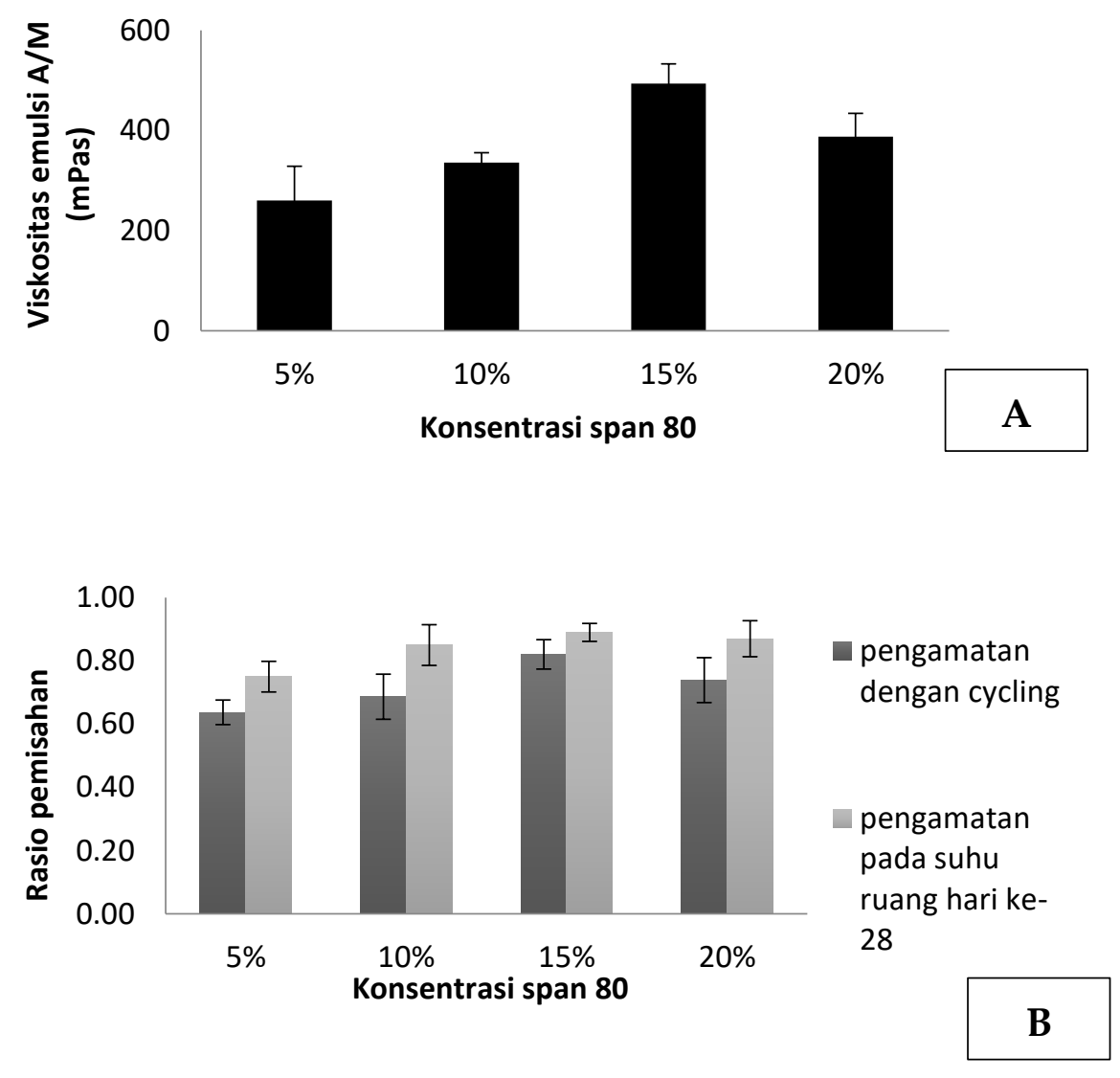

Gambar 2. Grafik viskositas emulsi A/M pada masing-masing konsentrasi span 80 (A) dan rasio pemisahan emulsi A/M pada masing-masing konsentrasi span 80 (B)

\subsection{Emulsi ganda air-dalam minyak-dalam air (A/M/A)}

Emulsi ganda A/M/A yang dibuat memiliki fase kontinyu berupa air sehingga dapat menghantarkan arus listrik yang terlihat dari lampu yang menyala ketika uji determinasi tipe emulsi. Emulsi ganda A/M/A dengan konsentrasi CMC Na sebesar 1\%, 2\%, dan 3\% menunjukkan nyala lampu pada alat uji.

Droplet minyak pada emulsi A/M/A (Gambar 3) secara mikroskopi nampak berukuran lebih besar yang di dalamnya terdapat droplet air fase internal. Selain itu, ukuran droplet emulsi ganda 
juga nampak lebih beragam. Peningkatan konsentrasi CMC Na 1-3\% pada emulsi ganda nampak tidak mempengaruhi ukuran droplet fase minyak dan variasi ukuran droplet nya. CMC Na umumnya lebih diketahui berfungsi sebagai stabilisator fase eksternal emulsi ganda A/M/A. Kemampuannya untuk untuk memperkecil ukuran droplet minyak relatif kecil karena CMC Na hanya mempunyai aktivitas fungsi penurun tegangan permukaan yang relatif kecil [5].
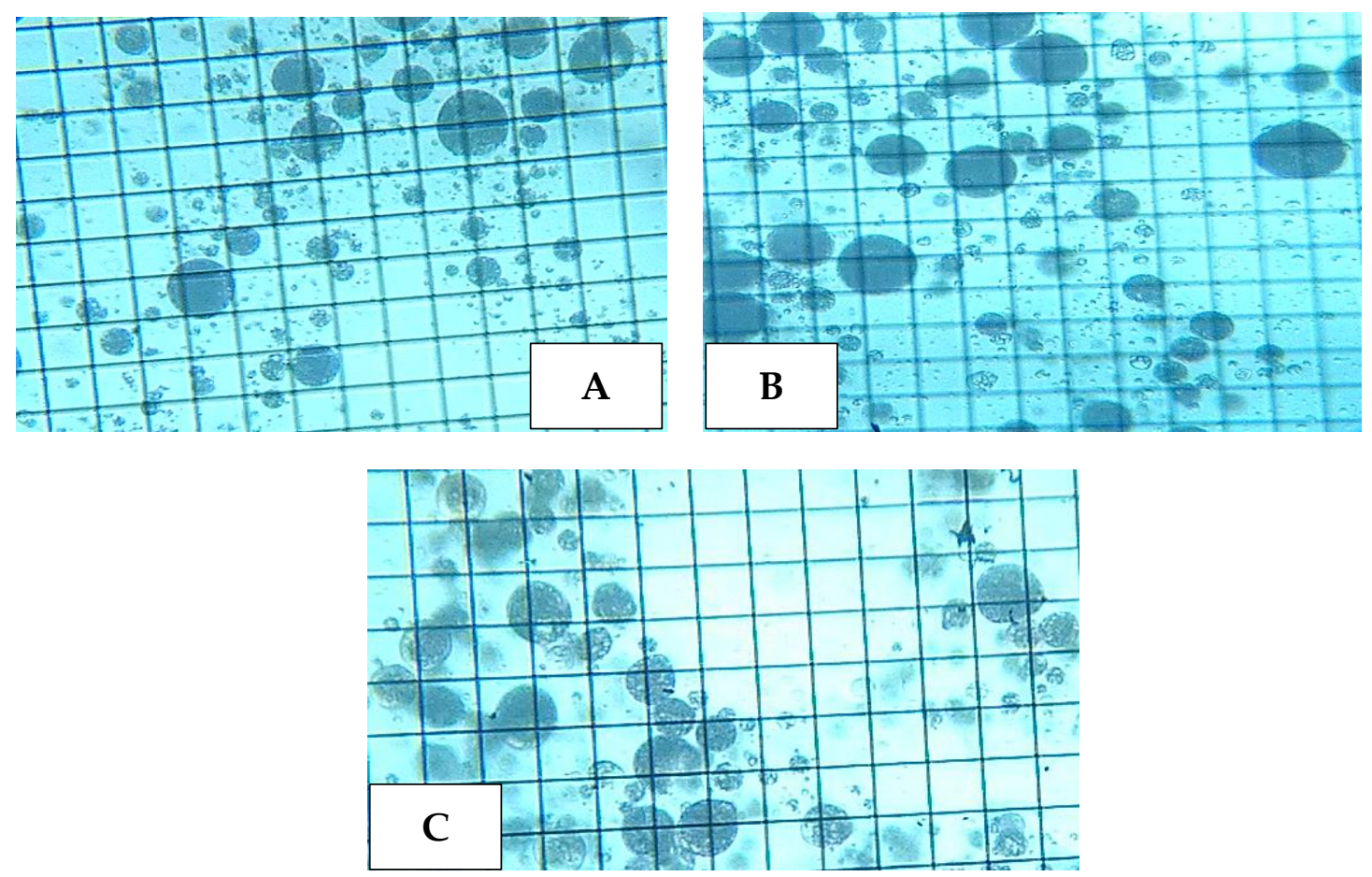

Gambar 3. Mikroskopi emulsi ganda air-dalam minyak-dalam air (A/M/A) dengan CMC Na konsentrasi 1\% (A), 2\% (B), dan 3\% (C) (perbesaran mikroskopi 150x)

Hubungan antara viskositas dan konsentrasi CMC Na pada emulsi A/M/A ditampilkan oleh Gambar 4A. Viskositas emulsi A/M/A meningkat seiring dengan meningkatnya konsentrasi CMC Na. Emulsi ganda A/M/A dengan kadar CMC Na 1, 2, dan 3\% menghasilkan viskositas emulsi berturut-turut 2565,0 \pm 96,7; 2610,0 $\pm 116,6$; dan 3059,0 \pm 41,2 mPas. Viskositas emulsi ganda dengan $3 \%$ CMC Na menunjukkan perbedaan yang signifikan dengan emulsi ganda 1\% CMC Na maupun emulsi ganda $2 \% \mathrm{CMC} \mathrm{Na}(\mathrm{p}<0,05)$. CMC Na merupakan polimer hidrokoloid yang dapat meningkatkan viskositas fase air eksternal pada emulsi ganda A/M/A. Semakin tinggi kadar CMC Na maka viskositas fase air eksternal emulsi akan semakin besar sehingga mengurangi pergerakan droplet dan mencegah terjadinya flokulasi dan/atau koalesensi [2].

Emulsi ganda A/M/A dan emulsi primer A/M dengan span 80 15\% diuji pelepasan zat warna larut air dengan menggunakan Ponceau $4 \mathrm{R}$ sebagai modelnya. Untuk keperluan ini, kadar Ponceau 4R hasil uji pelepasan dari emulsi ganda dianalisis dengan metode spektrofotometri UV/Vis. Panjang gelombang serapan maksimum Ponceau $4 \mathrm{R}$ yang terukur adalah $508 \mathrm{~nm}$. Persamaan kurva baku yang diperoleh adalah $y=31,80 x+0,027\left(R^{2}=0,9963\right)$ dengan limit batas kuantifikasi sebesar 0,148 $\mu \mathrm{g} / \mathrm{ml}$. Persentase Ponceau 4R terlepas dari emulsi A/M dan A/M/A ditampilkan oleh Tabel III. Persentase Ponceau 4R terdifusi dari emulsi A/M maupun emulsi A/M/A sangat rendah. Persentase pelepasan Ponceau $4 \mathrm{R}$ tidak berbeda signifikan antara emulsi A/M/A dengan konsentrasi CMC Na 1, 2, dan 3\% (p>0,05). CMC Na merupakan hidrokoloid yang lebih berfungsi sebagai stabilisator emulsi ganda melalui mekanisme peningkatan viskositas air fase eksternal. Kecilnya aktivitas 
penurunan tegangan antar muka oleh CMC Na kemungkinan menyebabkan tidak adanya pengaruh perbedaan konsentrasi CMC Na pada ukuran droplet minyak. Selain itu, besarnya pelepasan Ponceau $4 R$ juga tidak berbeda signifikan $(p>0,05)$ pada semua emulsi ganda dengan perbedaan konsentrasi CMC Na dibandingkan pada emulsi primer A/M dengan span 80 15\%. Hal ini mengindikasikan bahwa proses pembuatan emulsi ganda dan komposisi emulsi ganda A/M/A mampu mempertahankan karakteristik emulsi primer A/M sehingga menghasilkan pelepasan Ponceau $4 \mathrm{R}$ yang tidak berbeda signifikan. Kestabilan karakteristik emulsi primer A/M sangat menentukan tingkat enkapsulasi senyawa dalam fase air internal yang selanjutnya mempengaruhi profil pelepasan zat warna larut air dari droplet air internal emulsi ganda A/M/A [18].

Tabel 3. Persentase pelepasan zat warna Ponceau $4 \mathrm{R}$ dari emulsi A/M dan A/M/A

\begin{tabular}{cc}
\hline Emulsi & Pelepasan Ponceau 4R (\%) \pm SD \\
\hline A/M span $8015 \%$ & $0,03 \pm 0,01$ \\
A/M/A CMC Na 1\% & $0,06 \pm 0,01$ \\
A/M/A CMC Na 2\% & $0,06 \pm 0,01$ \\
A/M/A CMC Na 3\% & $0,09 \pm 0,03$ \\
\hline
\end{tabular}
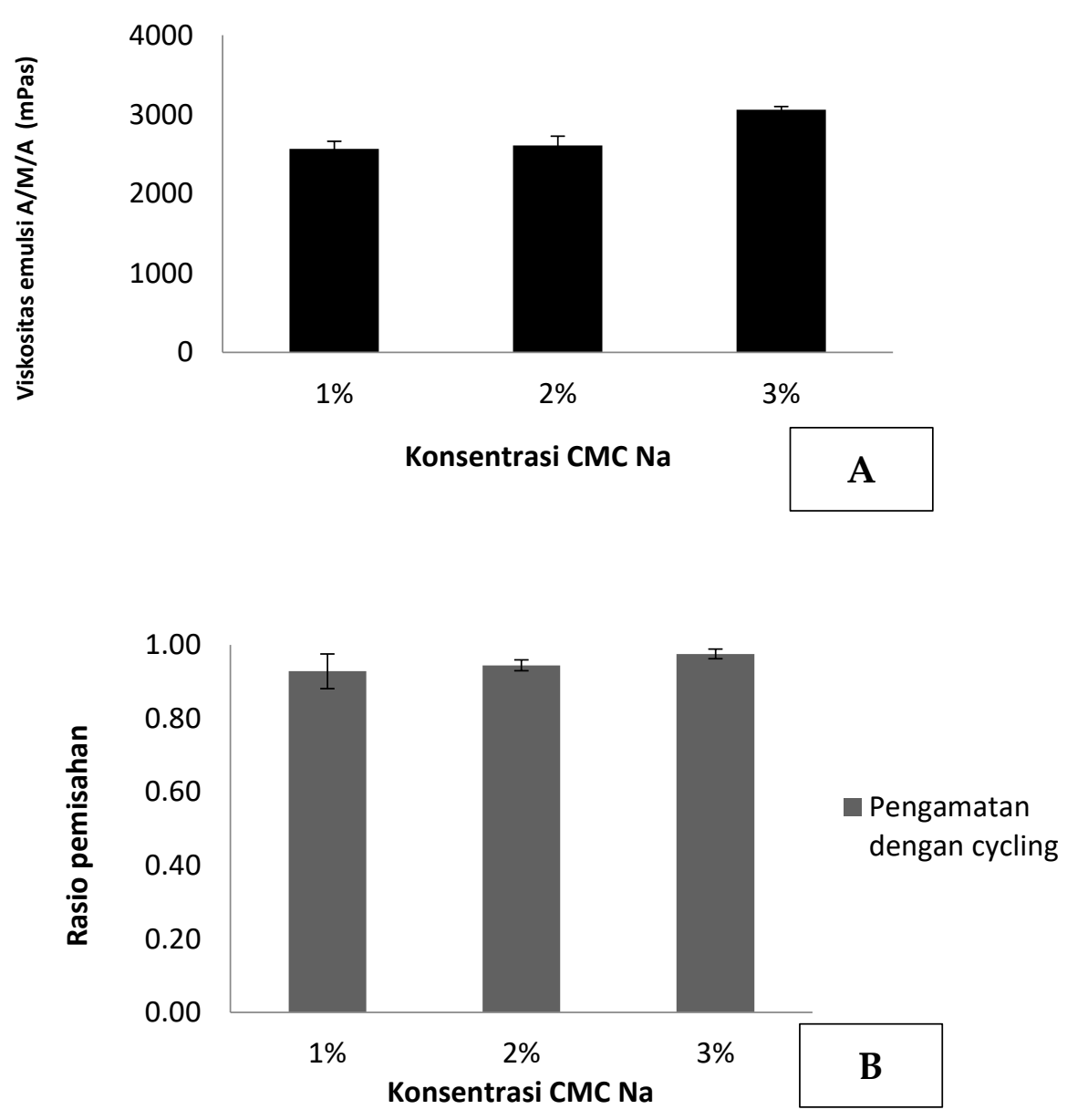

Gambar 4. Grafik viskositas (A) dan rasio pemisahan (B) emulsi ganda A/M/A pada masing-masing konsentrasi $\mathrm{CMC} \mathrm{Na}$ 
Uji stabilitas bertujuan untuk mendapatkan informasi mengenai kualitas produk dalam penyimpanan dengan adanya pengaruh lingkungan seperti suhu, kelembaban, atau cahaya [11, 19]. Pemisahan fase emulsi ganda A/M/A pada berbagai konsentrasi CMC Na setelah siklus heating cooling cycling dapat diamati pada Gambar 4B. Emulsi A/M/A memiliki stabilitas yang lebih baik daripada emulsi A/M. Emulsi ganda A/M/A mempunyai viskositas yang lebih tinggi daripada emulsi primer A/M sehingga memiliki laju pemisahan yang lebih kecil [20]. Emulsi ganda dengan konsentrasi CMC Na 3\% memiliki viskositas paling tinggi sehingga pemisahan fasenya lebih kecil dibandingkan emulsi dengan konsentrasi CMC Na 1\% dan 2\%. Meskipun demikian rasio pemisahan emulsi ganda dengan konsentrasi CMC Na yang berbeda tidak menunjukkan perbedaan yang signifikan ( $p>0,05)$. CMC Na meningkatkan viskositas fase air eksternal sehingga dapat mengurangi koalesensi droplet minyak [2].

\section{KESIMPULAN}

Emulsi ganda A/M/A dapat dibuat menggunakan CMC Na sebagai stabilisator emulsi. Emulsi primer A/M dengan konsentrasi span 80 sebesar 15\% menghasilkan emulsi primer yang paling stabil, droplet air fase internal yang nampak kecil dan viskositas yang tertinggi. Emulsifikasi emulsi primer $\mathrm{A} / \mathrm{M}$ ini ke dalam fase air dengan variasi konsentrasi $\mathrm{CMC}$ Na 1, 2, dan 3\% menghasilkan emulsi ganda A/M/A dengan stabilitas yang tidak berbeda bermakna. Viskositas emulsi ganda A/M/A meningkat secara signifikan pada emulsi ganda dengan 3\% CMC Na. Semua emulsi ganda A/M/A menghasilkan pelepasan model zat warna larut air (Ponceau 4R) yang kecil setelah 6 jam dan mengindikasikan kegunaan emulsi ini untuk penghantaran lepas lambat. Emulsi ganda A/M/A memiliki stabilitas fisik yang baik setelah uji heating-cooling cycle.

\section{Referensi}

1. Chouaibi, M., Mejri, J., Rezig, L., Abdelli, K., Hamdi, S., Experimental study of quercetin microencapsulation using water-in-oil-in-water (W1/O/W2) double emulsion. Journal of Molecular Liquids 2019,273, 183-191.

2. Matos, M., Gutiérrez, G., Coca, J., Pazos, C., Preparation of water-in-oil-in-water (W1/O/W2) double emulsions containing trans-resveratrol. Colloids and surfaces A: physicochemical and engineering aspects 2014,442, 69-79.

3. Schuch, A., Wrenger, J., Schuchmann, H. P., Production of W/O/W double emulsions. Part II: Influence of emulsification device on release of water by coalescence. Colloids and Surfaces A: Physicochemical and Engineering Aspects 2014,461, 344-351.

4. Sapei, L., Naqvi, M. A., Rousseau, D., Stability and release properties of double emulsions for food applications. Food hydrocolloids 2012,27, 316-323.

5. Schuch, A., Helfenritter, C., Funck, M., Schuchmann, H., Observations on the influence of different biopolymers on coalescence of inner water droplets in $\mathrm{W} / \mathrm{O} / \mathrm{W}$ (water-in-oil-in-water) double emulsions. Colloids and Surfaces A: Physicochemical and Engineering Aspects 2015,475, 2-8.

6. Klojdová, I., Troshchynska, Y., Štětina, J., Influence of carrageenan on the preparation and stability of w/o/w double milk emulsions. International Dairy Journal 2018,87, 54-59.

7. Schmidts, T., Dobler, D., Nissing, C., Runkel, F., Influence of hydrophilic surfactants on the properties of multiple W/O/W emulsions. Journal of colloid and interface science 2009,338, 184-192. 
8. Chan, S. W., Mirhosseini, H., Taip, F. S., Ling, T. C., Tan, C. P., Stability of CoQ10-loaded oil-in-water $(\mathrm{O} / \mathrm{W})$ emulsion: effect of carrier oil and emulsifier type. Food biophysics 2013,8, 273-281.

9. Pudyastuti, B., Marchaban, M., Kuswahyuning, R., Pengaruh Konsentrasi Xanthan Gum terhadap Stabilitas Fisik Krim Virgin Coconut Oil (VCO). Jurnal Farmasi Sains dan Komunitas (Journal of Pharmaceutical Sciences and Community) 2016,12.

10. Kale, S. N., Deore, S. L., Emulsion micro emulsion and nano emulsion: a review. Systematic Reviews in Pharmacy 2017,8, 39 .

11. Estanqueiro, M., Conceição, J., Amaral, M. H., Santos, D., Silva, J. B., Lobo, J. M. S., Characterization and stability studies of emulsion systems containing pumice. Brazilian Journal of Pharmaceutical Sciences 2014,50, 361-369.

12. Hendriati, L., Nugroho, A. K., Optimasi Asam Oleat, Propilen Glikol dan Iontoforesis Terhadap Transpor Transdermal Propranolol HCl. Jurnal Farmasi Indonesia 2012,6, 21-29.

13. Kharat, M., Zhang, G., McClements, D. J., Stability of curcumin in oil-in-water emulsions: Impact of emulsifier type and concentration on chemical degradation. Food Research International 2018,111, 178186.

14. Vasiljevic, D., Parojcic, J., Primorac, M., Vuleta, G., An investigation into the characteristics and drug release properties of multiple $\mathrm{W} / \mathrm{O} / \mathrm{W}$ emulsion systems containing low concentration of lipophilic polymeric emulsifier. International journal of pharmaceutics 2006,309, 171-177.

15. Bajaj, S., Singla, D., Sakhuja, N., Stability testing of pharmaceutical products. J App Pharm Sci 2012,2, 129-138.

16. Baby, A. R., Migliato, K. F., Maciel, C. P. M., Zague, V., Pinto, C. A. S. d. O., Salgado, H. R. N., Kaneko, T. M., Velasco, M. V. R., Accelerated chemical stability data of O/W fluid emulsions containing the extract of Trichilia catigua Adr. Juss (and) Ptychopetalum olacoides Bentham. Revista Brasileira de Ciências Farmacêuticas 2007,43, 405-412.

17. Chen, G., Tao, D., An experimental study of stability of oil-water emulsion. Fuel processing technology 2005,86, 499-508.

18. Schuch, A., Deiters, P., Henne, J., Köhler, K., Schuchmann, H. P., Production of W/O/W (water-in-oilin-water) multiple emulsions: droplet breakup and release of water. Journal of colloid and interface science 2013,402, 157-164.

19. Restu, W. K., Sampora, Y., Meliana, Y., Haryono, A., Effect of accelerated stability test on characteristics of emulsion systems with chitosan as a stabilizer. Procedia Chemistry 2015,16, 171-176.

20. Leal-Calderon, F., Schmitt, V., Bibette, J., Emulsion science: basic principles. (Springer Science \& Business Media, 2007).

(C) 2020 by the authors. Submitted for possible open access publication under the terms and conditions of the Creative Commons Attribution (CC BY) license (http://creativecommons.org/licenses/by/4.0/). 